\title{
Ventral Incisional Hernia Mesh Infection: Surgical Management
}

\author{
Dr. Mukesh Kumar*;Dr Nibha Kumari \\ *Department Of Surgery, VMMC \&Safdarjung Hospital, New Delhi, INDIA
}

Abstract: Prosthetic mesh infection is catastrophic complication of ventral incisional Hernia (VIH) repair. Sur gical literature was reviewed to determine the risk factor, microbiology and treatment of mesh infection.

Keywords: Mesh Infections; Hernial Repair Treatment

\section{Introduction}

Within the last few years the use of mesh for repair of various types of hernia has become a standard pr actice. ${ }^{1}$ The incidence of recurrence has gone down significantly making this a gold standard for hernia repair. ${ }^{2,3}$ However in the event of infection developing a series of catastrophic events ranging from localized swelling an $\mathrm{d}$ redness to severe sepsis with fistula formation can develop. ${ }^{1,3}$ Identifying the various factors which may predis pose to infection can prevent such septic calamities. ${ }^{4}$ A case of laparoscopic mesh infection treated by a two stag ed surgical procedure is presented with a review of literature.

\section{Case Report}

A 58 year old obese male patient was came to our hospital for the management of incisional hernia foll owing exploratory laparotomy for small bowel perforation three year back. For which extraperitonial hernia mes $\mathrm{h}$ repair done in our hospital. Four weeks after the surgery, the patient developed swelling and redness at the stit ched line. There is seroma collection at side of main line incision and it was aspirated and the negative suction $\mathrm{d}$ rain applied and coverage of antibiotic after fluid culture and sensitivity. Drain output was 250-270 CC per day and decreasing gradually to $65-80 \mathrm{cc}$ per day. After sometime, it becomes purulent. Blood investigation revealed neutrophilic leukocytosis.

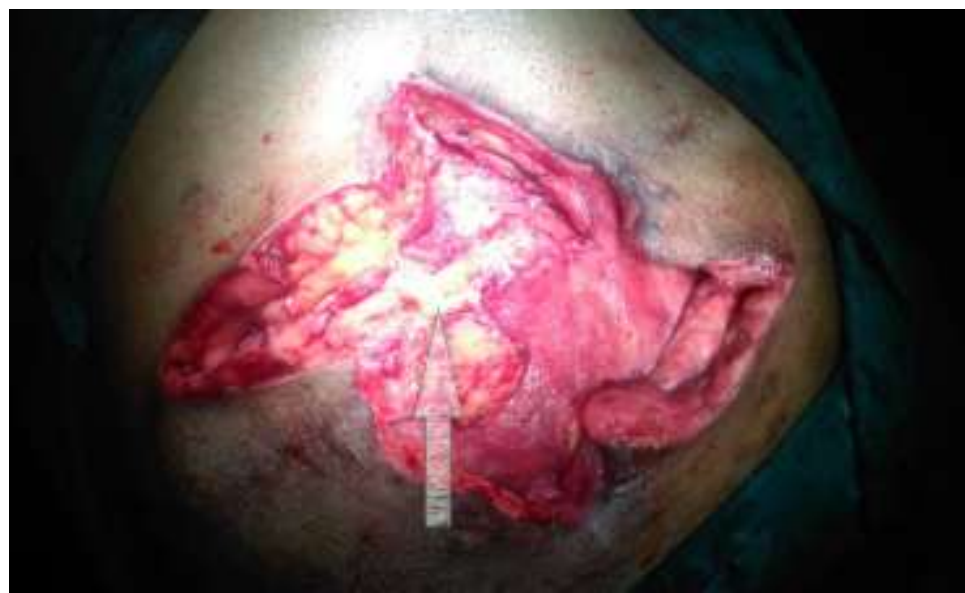

Figure 1: Infected PTFE Mesh with walled of fibrous cavity

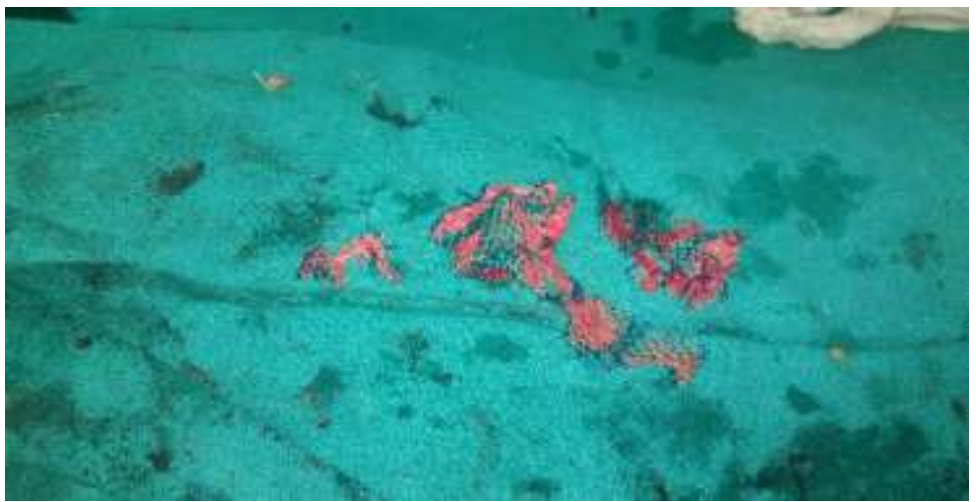

Figure 2: Infected explanted mesh 
Other blood investigations like blood sugar, liver function test and kidney function test were within nor mal limit. Firstly, wound was explored and necrotic skin was debrided and consequently dressing done. Pus bec omes serosangunous and sterile after proper antibiotic coverage. Second stage, explantation of infected PTFE $m$ esh which was extra-peritonial. The infected area was debrided and irrigated. The wound was left opened and ne gative suction applied. After that, regular dressing applied and wound healed by secondary intention. The patien $\mathrm{t}$ is following up for last 6 months with no hernia.

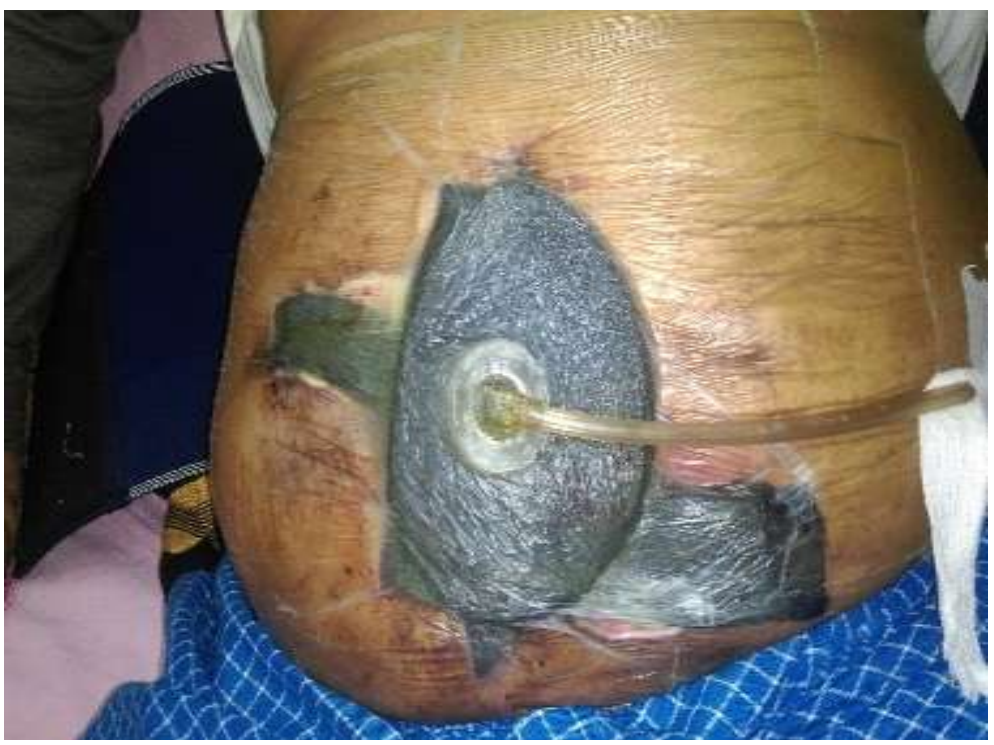

Figure 3: Negative pressure wound therapy after mesh explantation

\section{Discussion}

Various factors play a significant role in the development of mesh infections. ${ }^{1-3}$. Risk factors like high BMI (obesity), chronic obstructive disease (COPD), prior surgical site infection, performance of other procedure via same incision at the time of repair, longer operative time, lack of tissue coverage of the Mesh, enterotomy a nd enterocutaneous fistula and use of larger, microporous or expanded polytetrafluoroethylene mesh.

\section{Type of Mesh}

The search for ideal material for a mesh continues, however none of material available till date can be $\mathrm{d}$ escribed as ideal. Nature of material of the mesh is an important factor. PTFE meshes are associated with higher incidence of infection and fistula formation as was evident in the case presented. Nature of filament of the mesh also affects the chance of infection. Monofilament meshes such as polypropylene or light weight meshes are less prone to develop infections, however multifilament meshes such as polyesters lead to increase bacterial persiste nce or spread of infection as well.

\section{Porosity of mesh}

Micro porous meshes are associated with high rates of infection as well as development of seroma, whe reas macro porous meshes are associated with lower incidence of infection but with higher incidence of adhesio ns and erosive events. Micro pore mesh has a pore diameter of less than $10 \mu \mathrm{m}$. As a result bacteria can penetrat e the mesh easily, but leukocytes cannot as there mean size is $75 \mu \mathrm{m}$. The result is that these bacteria are shielde $\mathrm{d}$ from the immunological defenses of the patient. Water contact angle or wettability of a mesh determines the ea se with which bacteria can get attached to the mesh. Mesh with high contact angle is considered hydrophobic an $\mathrm{d}$ as a result the chances of bacterial attachment are significantly less. A material with low water contact angle e xhibits a hydrophilic nature and so is more prone to attachment by bacteria. However mixed results have been $o$ bserved with respect to this particular criterion. Awareness of the pathophysiology of microbiological aspects of mesh infections is important for treatment. ${ }^{4,5}$ Staphylococcus aureus is still the commonest organism.

In addition to $\mathrm{S}$. aureus other organism encountered are Streptococcus species, Enterobacteriaceae and anaerobic bacteria such as Peptostreptococcus. Infections with atypical mycobacteria are encountered in laparos copic procedures. The presence of a foreign material decreases the local immunity thereby decreasing the numb er of bacteria needed to cause infection. ${ }^{6}$ Co morbid medical conditions significantly hamper immunological def ense mechanisms in the host. ${ }^{7}$ Bacteria get attached to foreign material. They proliferate and form a bio film all around the synthetic material. The bio film contains a wide spectrum of bacteria which release an exopolysaccha 
ride component. This component provides an excellent skeletal structure which exerts a protective effect for bac teria not only against antibiotics but also against a host defense mechanism.

High grade sterilization of scopes may not be practised in all centres. Instead most centres rely on high grade disinfection with glutaraldehyde after rinsing with ordinary potable water. The chance of water born organ isms causing infection also increases. This includes atypical mycobacterium and pseudomonas. The use of disinf ection without meticulous bacterial decontamination in this situation is another factor contributing to mesh infec tion.Adequate rinsing of instruments followed by vigorous sterilization ideally by autoclaving is essential for pre vention of infection by atypical mycobacterium.Despite use of povidone-iodine scrub yet infection continues to $t$ hrive especially at umbilical site.The use of fresh solution can help to reduce contamination there by reducing in fection rate in hernia surgery.Clinical manifestation of mesh infection develops anywhere from 2 weeks to $14 \mathrm{~m}$ onths. ${ }^{2,3}$ Clinical features typically suggestive of local inflammation characterized by pain, redness, tenderness, $\mathrm{s}$ welling and raised local temperature. Systemic features may be fever associated with chills and malaise. In a fe w cases mesh related infection may present as a fistula discharging pus or an intra-abdominal abscess as seen in laparoscopic mesh infection. An accurate diagnosis has to be made with respect to the extent and severity of infe ction. Involvement of adjacent organs in close vicinity especially in abdominal cases needs to be determined.Ha ematological investigations will show anaemia in chronic infection and raised neutrophils. A contrast enhanced CT scan will identify the site of collection, extent of the induration mass, status of mesh and involvement of any adjacent organ system. ${ }^{7,8}$ A combined medical and surgical approach is the preferred strategy for management.I ntravenous antibiotics are essential to begin with. However it may not lead to a complete cure as penetration of $t$ he fibrous capsule surrounding the mesh is difficult. Hence surgical approach is inevitable and mandatory. ${ }^{9}$

Two stage surgical approach yields better success as was done in the case presented. The first stage co mprising of a release incision to drain the pus in the infected area. This allows reduction in the inflammatory pro cess there by reducing the severity of induration. Once volume of discharge decreases, the extent of induration is reduced and systemic signs of infection resolve one can proceed to the second stage of surgical intervention. The second stage comprises of removal of mesh. In majority of cases the mesh lies floating in a pool of pus and debr is. This cavity has to be access followed by removal of mesh and evacuation of all purulent and particulate debri s. A good scraping of abscess cavity will enhance the healing process. It is preferable to allow thewound to heal by secondary intention as it causescomplete resolution of the infection process. Secondarysuturing can be done once healthy ranulation has set in.However in case of midline abdominal wall infections,primary closure needs $\mathrm{t}$ $\mathrm{o}$ be done with acceptance of thefact that wound infection and development of anincisional hernia at a later date is inevitable in mostcases. ${ }^{11}$ There is high likelihood of hernia recurrence aftersuch a surgical intervention. Patie nt needs to be informedin advance of this outcome.A two staged approach is therefore the best option for thetrea tment of infected mesh. It reduces the chances ofdamage to adjacent and underlying viscera and alsoprevents ex cessive loss of overlying tissue including skin.

\section{Preventive strategies}

Preventive strategies are absolutely essential before embarking on a mesh repair for hernia. Proper sele ction of patient ensuring good control of comorbid medical conditions and absence of any sort of infection. ${ }^{12} \mathrm{Rig}$ id sterilization by autoclaving of both instruments and scopes. Meticulous technique of dissection with periodic i rrigation of operative site with normal saline during the course of surgery. Meticulous haemostasis before closur e. However if doubt still persist in cases which involve extensive dissection, it is advisable to keep a negative su ction drain in order to prevent formation of a seroma which can serve as an ideal nidus for infection. ${ }^{12,13}$

\section{Conclusion}

Prevention is the best management, evolving on case by case from explantation towards mesh salvage, to prevent complication - hernial recurrence. A two stage surgical approach is the gold standard for treating mes $\mathrm{h}$ infections

\section{References}

[1]. Taylor SG, O’Dwyer PJ. Chronic groin sepsis following tension free inguinal hernioplasty. Br J Surg. 1999;86:562-5.

[2]. Mathew MR, Caruso DM, Tsujimura RB, Smilack JD, Pockaj BA, Malone JM. Ventral hernia synthetic mesh repair inected by Mycobacterium fortuitum. Am Surg. 1999;65:1035-7

[3]. Coring H, Waldner H, Emmerling P, Abele Horn M. Chronic fistulating wound infection after Lichtenstein repair of inguinal hernia, caused by a small colony variant of Staphylococcus aureus. Der Chirurg. 2001;72:441-3.

[4]. Deysine M. Pathophysiology, prevention and management of prosthetic infections in hernia surgery. SurgClin North Am. 1998; 78:1105-15.

[5]. Troy MG, Dong QS, Dobrin PB, Hecht D. Do tropical antibiotics provide improved prophylaxis against bacterial growth in the presence of polypropylene mesh? Am J Surg. 1996;171:391-3.

[6]. Lazorthes F, Chiotasso P, Massip P, Materre JP, Sakissian M. Local antibiotic prophylaxis in inguinal hernia repair. SurgGynecol Obstet. 1992;175:569-70.

[7]. Buret A, Ward KH, Olson ME, Costerton JW. An in vivo model to study the pathobiology of infectious biofilms on biomaterial surfaces. J Biomed Mater Res. 1991;25:865-74. 
[8]. Sohail MR Smilack JD. Hernia repair mesh associated Mycobacterium goondiiinfection. 2004;42:2858-60.

[9]. Kathju S, Nistico L, Melton Kreft R, Lasko LA, Stoodley P. Direct demonstration of bacterial biofilms on prothetic mesh after ventral herniorhaphy. Surg Infect (Larchmt). 2015;16:45-53.

[10]. Slomka JM, Laker S, Chandrasekar P, Pauli DE. Failure to obtain microbiologic culture and its consequences in a mesh related infection. BMJ Case Rep. 2013;2013:pii-bcr 2013009123

[11]. Samee A, Adjepong S, Pattar J. Late onset mesh infection laparoscopic inguinal herniarepair. BMJ Case Rep. 2011;2011:pii-bcr 0920114863

[12]. Vagholkar K, Budhkar A. Combined tissue and mesh repair for midline incisional hernia. J Med SciClin Res. 2014;2(8):1890-900.

[13]. Vagholkar K, Iyengar M, Vagholkar S. Single staged surgical procedure for recurrent incisional hernia with tropic ulceration: a viable surgical option. IntSurg J. 2016;3(1):357-60. 